\title{
La filosofía de la religión de Zubiri y diálogos con el sonido y la música
}

\author{
Zubiri's philosophy of religion and dialogs with sound and music
}

\author{
Romina González Romanini \\ Magíster en Musicología Latinoamericana \\ Universidad Alberto Hurtado \\ romigonzalezr@gmail.com \\ Fecha de recepción: 01/03/2019 \\ Fecha de aprobación: 26/03/2019
}

Como citar este artículo: R.. GONZÁLEZ. "La filosofía de la religión de Zubiri y diálogos con el sonido y la música" en Palabra y Razón. Revista de Teología, Filosofía y Ciencias de la Religión Nº15, Julio 2019, pp. 43-59 https://doi.org/10.29035/pyr.15.43

Resumen: Este trabajo resume gran parte de la filosofía de la religión de Xavier Zubiri desde Inteligencia Sentiente, centrándose especialmente en el aspecto de la religación como hecho inmediato situado en la aprehensión, y sus plasmaciones religiosas que serán probadas mediante la experiencia en la realidad. Desde esta experiencia religiosa se proponen también algunos diálogos con el sonido y la música, poniendo atención en lo que sucede con los fenómenos de audición y escucha.

Palabras claves: Filosofía de la religión, religación, religión, música, sonido, escucha.

Abstract: This paper resumes a great part of Xavier Zubiri's philosophy of religion read from Sentient Intelligence, focusing specially on the aspect of religation as an immediate fact placed in apprehension, and its religious plasmations that will be proved through experience in reality. From this religious experience it is also proposed some dialogs with sound and music, putting attention on what happens with audition and listening phenomena.

Key words: Philosphy of religion, religation, religion, music, sound, listening. 


\section{Filosofía de la Religión de Xavier Zubiri}

La obra Inteligencia Sentiente de Zubiri, correspondiendo a una noología, se trata de una investigación del inteligir sentiente o del sentir intelectivo, de un análisis filosófico del hecho más básico y común a toda vida sentiente que es la aprehensión. En este vivir, que es un proceso unitario básico, se distinguen tres momentos: la suscitación, la modificación tónica y la respuesta, o dicho de otro modo: intelección, sentimiento y volición. Toda vida sentiente pende del momento de suscitación y como sea la suscitación será el vivir. La suscitación es la aprehensión de algo. Aquí yace la filosofía primera - usando las palabras de Diego Gracia- pues lo más radical de nuestra vida son los actos aprehensivos y todo lo que venga después supondrá el saber primero sobre estos actos.

Poniendo el foco en la suscitación o aprehensión, podemos decir que también posee una estructura tríadica, en donde se diferencian: afección, alteridad y fuerza de imposición. Lo suscitante en la aprehensión nos afecta, por tanto la afección se trata de un momento impresivo. En el acto mismo, aprehendemos que lo que nos afecta es algo "otro", por tanto corresponde al segundo momento de alteridad. Y finalmente, aquello que nos afecta, lo hará con una fuerza de imposición.

Por otro lado, Zubiri identifica dos tipos de aprehensión que tienen que ver con la alteridad aprehendida, y como esas alteridades son diferentes, las aprehensiones lo serán también. Existe entonces, un contenido y una formalidad. El contenido será complejo, en donde aprehendemos notas e intensidades; y una formalidad que es el modo de quedar lo aprehendido en la aprehensión donde aprehendemos estimulidad y realidad. La estimulidad será aquella aprehensión de los animales, que aprehenden signos objetivos para la respuesta viviente, y la realidad la aprehensión del hombre, en donde lo que se aprehende no sólo es alteridad sígnica, sino alteridad radical que queda en el hombre y en lo otro mismo como siendo "de suyo".

El ser humano entonces queda abierto a lo real como tal, abierto a las cosas reales, y será para Zubiri el "animal de realidades". Este "animal de realidades" al aprehender impresivamente algo, siente, siendo la aprehensión humana una impresión de realidad, un acto de sentir, un acto de inteligir, o mejor dicho, de inteligir sentiente o sentir intelectivo.

Así, la esencia del acto de aprehensión consistirá en la mera actualización de realidad, pues por la aprehensión el hombre queda inadmisiblemente instalado en la realidad. Todo el sentir humano resulta liberado de la presión estimúlica. La 
afección humana es afección real, la alteridad en el hombre es realidad y la fuerza de imposición es fuerza de realidad ${ }^{1}$. La apertura de la esencia humana reposa en la intelección, pues ella es la que nos fuerza a vivir pensando. La apertura libera al hombre de toda sujeción estimúlica y hace de su esencia una persona, por ello la "personeidad" es el preciso carácter de la esencia intelectiva abierta ${ }^{2}$. El hombre es suyo porque posee su realidad en tanto que realidad, por eso es "suidad". "El proceso de sentir se abre, las tendencias se vuelven inconclusas y la respuesta humana queda entonces indeterminada [...]. En el hombre la respuesta queda en suspenso. Es la realidad de la volición. El hombre es libre y ha de escoger su respuesta"3.

Volviendo al hecho central que es la aprehensión, Enzo Solari resume que:

"Por aprehender impresivamente la realidad de las cosas, el hombre tiene un sentir intelectivo. Por ser una inteligencia sentiente, es un animal de realidades. Por vivir en el ámbito de la realidad y estar liberado de la tiranía estimúlica, el hombre es persona. Por ser formalmente suyo, el hombre tiene una dimensión histórica y una estructura moral, y ha de realizarse a través de la apropiación de posibilidades. Sin embargo esto no es todo. Y es que la impresión de realidad, como acaba de insinuarse, está dotada de un carácter insondable y poderoso. La realidad presente en toda aprehensión humana de las cosas, tiene por ello un carácter intrínsecamente enigmático"4.

Aquí es donde emerge la fuerza de imposición de la realidad, porque el hombre está inundado, forzado por esta fuerza de imposición de lo real. La fuerza de imposición es entonces la fuerza de realidad. Lo quiera o no, el ser humano padece la realidad en todos y cada uno de sus actos, por ello la fuerza de imposición tiene una estructura trascendental, y la impresión humana, por ser impresión de realidad, está abierta y es trascendental. En cada cosa la realidad tiene un poder dominante: las cosas reales vehiculan trascendentalmente el poder mismo de lo real, hay dominancia de la formalidad sobre el contenido ${ }^{5}$. El poder de realidad, dotado de primacía frente a todas las cosas, domina al hombre de una manera peculiar, pues le impone la inexorable tarea de tener que realizarse de una manera $u$ otra $^{6}$.

Ahora bien, en la medida que el hombre aprehende realidad, todo lo aprehende como "otro" respecto de su persona. Es así, un absoluto relativo. Absoluto porque

\footnotetext{
${ }^{1}$ E. SOLARI. La raiz de lo sagrado. Contribuciones de Zubiri a la filosofia de la religión. RIL Editores: Santiago, 2010, p. 133.

${ }^{2}$ E. SOLARI. La raíz de lo sagrado, p. 134.

${ }^{3}$ E. SOLARI. La raíz de lo sagrado, p. 135.

${ }^{4}$ E. SOLARI. La raíz de lo sagrado, p. 139.

${ }^{5}$ E. SOLARI. La raíz de lo sagrado, p. 141.

${ }^{6}$ E. SOLARI. La raiz de lo sagrado, p. 142.
} 
como persona se autoposee como realidad y se autodetermina en sus decisiones, pero relativamente, pues su autoposesión con la realidad es a través de las cosas, en el mundo.

"El hombre es un absoluto, pues posee su propia realidad y es por ello persona. Pero esta absolutidad está referida a las cosas, es decir, a todo lo demás: cosas apersonales y personales, incluida la propia persona. [...] Es la necesidad de las cosas para ser absoluto, la necesidad insoslayable de todo lo demás como de un término que constituye a la persona humana. Justamente en esto consiste la relatividad de la absolutidad humana"

El hombre, relativamente absoluto, se encuentra apoyado en la realidad pura y simple. Esta realidad es entonces fundamento. Zubiri distingue tres momentos: la ultimidad de lo real, en donde la realidad es lo último de las cosas y de mis propias acciones; la posibilitancia de lo real, donde la realidad es el ámbito mayor y definitivo dentro del cual el hombre esboza su vida; y finalmente la impelencia, pues la realidad es un carácter trascendental al que no se puede escapar, que impele al hombre a realizarse de una manera $u$ otra ${ }^{8}$. Para el hombre, pues, la realidad es fundamental, es decir, última, posibilitante e impelente. El origen de la idea de Dios radicará entonces en nuestro ser relativamente absoluto, siendo la divinidad lo único absolutamente absoluto.

Nosotros aprehendemos las cosas y las cosas ejercen una fuerza sobre nosotros. Nos llevan a hacer algo, empujan a hacer algo. Cada cosa aprehendida es un contenido más una fuerza de realidad, entonces lo que empuja es la realidad como tal que viene vehiculada en las cosas. La fuerza de realidad nos impele a realizar nuestros actos personales, por tanto será constitutivo de nuestro existir la pregunta ¿qué va a ser de mi? (basada en la realidad enigmática), ¿qué voy a hacer de mí? (basada en la libertad). La inquietud es constitutiva. Y en esto descubrimos que no somos fundamento de nosotros mismos, sino que estamos apoyados en una realidad enigmática y poderosa que nos desborda, y en esa inquietud surge la religación, pues la fuerza de realidad nos impele a vivir personalmente, por tanto existir es ser religado. La religación es experiencia radical constitutiva que nos liga al poder de lo real y que está tanto en el ateo, como en el agnóstico y en el teísta.

"El poder de lo real ejerce su dominio sobre el ser humano, de tal manera que este vive su vida aprehendiendo primordialmente el despliegue de ese poder enigmático. [...] Es el hombre el que está fundado en el poder de lo real, "apoderado" por él. [...] Este dominio adopta la forma de una atadura o ligazón. Es la "religación" de la persona al

${ }^{7}$ E. SOLARI. La raiz de lo sagrado, p. 176.

${ }^{8}$ E. SOLARI. La raiz de lo sagrado, pp. 177-178. 
poder de lo real. El hombre es la realidad personal religada. La religación, dice Zubiri, es la dimensión noérgica y poderosa descubierta en la aprehensión humana, y es a la vez y por lo mismo el hecho teologal primordial, el punto de partida de la religión, el primer dato de toda filosofía de la religión"9.

La religación será entonces aquel momento pre-religioso sobre el cual se fundará toda la parte fenomenológica de la filosofía de la religión de Zubiri, que será una reflexión rigurosa y articulada del "problema de Dios y no la cuestión ni de la existencia ni del concepto de Dios, sino sólo de la constitutiva y ontológica religación de la existencia"10. "La religación se halla en la propia existencia humana, y no fuera o más allá de ella y del mundo. El problema de Dios es una radical dimensión de la vida humana. El hombre consiste en el problema de Dios, lo que significa que es una existencia religada" ". La religación es como definiría Zubiri, un "arraigo de la existencia". Este arraigo está ligado con el apoyo y raíz de la persona, es decir, con su fundamento. La fundamentalidad es la dimensión de la existencia en cuya virtud se dice que el hombre está religado, radicado, apoyado.

En la apertura existencial se muestra la religación:

"y así como el estar abierto a las cosas nos descubre, en este su estar abierto, que "hay" cosas, así también el estar religado nos descubre que "hay" lo que religa, lo que constituye la raíz fundamental de la existencia”. [...] Si en un principio [Zubiri] decía que lo que religa es Dios, en el texto publicado en Naturaleza, Historia, Dios puntualiza y agrega "no nos es patente Dios, sino más bien la deidad". La deidad es el ámbito abierto por la religación"12.

Entonces esa deidad a la que estamos religados será una experiencia inmediata, pues se halla en la aprehensión, es inmanente a ella, mientras que la vivencia de una divinidad (Dios, dioses, cosmos) será una experiencia mediada, pues Dios no está accedido. Pero la pregunta por Dios sí que está inscrita en el fondo del ser humano, entonces la pregunta por la divinidad será universal, porque todo hombre está religado. "El hombre no tiene el problema de la deidad, pero sí tiene inexorablemente el problema de Dios, es decir, «el problema de quién es esa deidad»"13, pudiendo responder a ello agnósticamente, ateamente, o teístamente. Este es el terreno en común. Zubiri radica lo religioso en algo pre-religioso que

\footnotetext{
${ }_{9}^{9}$ E. SOLARI. La raíz de lo sagrado, p. 143.

${ }^{10} \mathrm{~F}$. CORREA. El inicial planteamiento zubiriano de la cuestión de Dios en su artículo "En torno al problema de Dios". Influencia heideggeriana y camino propio. https://scielo.conicyt.cl/scielo. php?script=sci_arttext\&pid=S0049-34492008000200011\#t32

${ }^{11}$ E. SOLARI. La raiz de lo sagrado, p. 144.

${ }^{12}$ E. SOLARI. La raíz de lo sagrado, p. 151.

${ }^{13}$ E. SOLARI. La raíz de lo sagrado, p. 158.
} 
es la religación, experiencia inmediata de la aprehensión frente al poder de lo real. Todos estamos religados, mas las religiones serán plasmaciones históricas, sociales y culturales de un hecho anterior que es la religación.

De esta forma, cuando el logos toma distancia y se pregunta en qué consiste ese poder de lo real al que estamos religados, el logos vuelve en un momento reversivo, pudiendo afirmar ese fundamento como divino (teísmo), negarlo (ateísmo) o dejarlo como indeterminado (agnosticismo). Cuando el logos construye y elabora ideas de divinidad, y afirma el fundamento de la divinidad, la religación se estaría plasmando en religión, conformándose así la vía teísta en el logos religioso. Cuando el logos dice que el fundamento no es Dios, no es divinidad, se plasma el logos ateo. Y cuando el logos afirma que el fundamento está indeterminado, se plasma el logos agnóstico. Si el logos afirma que el fundamento es divinidad, entonces se constituye el campo religioso, y se plasma la religación en religión. La religión tiene su origen entonces en el logos, ya no en la aprehensión.

Habiendo tres vías posibles de plasmación de la religación: teísmo, ateísmo y agnosticismo, seguiremos para efectos de este trabajo por la vía teísta que es la que Zubiri también continúa. Para él, cuando el logos afirma que el poder de lo real es Dios, afirma algo sobre el "de suyo", y cuando la razón marche a decir qué es este Dios en su fondo y tenga diferentes comprensiones de la divinidad, va a buscar lo que es Dios "de suyo", irá en búsqueda de la realidad de Dios allende la aprehensión. "Si Dios es la realidad absolutamente absoluta determinada por el logos y atestiguada por el lenguaje y la historia" ${ }^{14}$, la inteligencia tiene una tarea por delante: determinar su razón definitiva. "Mientras el conocer en general busca la realidad-fundamento de lo actualizado en el campo, el conocimiento religioso busca la realidad-fundamento del poder de lo real y de sus sentidos teístas campales"15.

Una vez hecha la pregunta del logos sobre qué es el poder de lo real y si este podría ser Dios, le queda a la razón marchar al mundo: esbozar posibilidades y verificar luego a través de la experiencia. Zubiri entra a desarrollar el método teísta, esbozando sus posibilidades. El teísmo tiene tres líneas de desarrollo básicas que serían según el autor, congéneres: una en que el logos en un proceso intelectivo afirma que el poder de lo real es Dios o lo divino (monoteísmo), o son los dioses (politeísmo), o el universo y leyes cósmico-morales (panteísmo). Zubiri optará por argumentar la vía monoteísta que según él, sería la más plausible y completa metafísicamente

\footnotetext{
${ }^{14}$ F. CORREA. El inicial planteamiento zubiriano de la cuestión de Dios en su artículo "En torno al problema de Dios". Influencia heideggeriana y camino propio. https://scielo.conicyt.cl/scielo. php?script $=$ sci_arttext\&pid=S0049-34492008000200011\#t32

${ }^{15}$ F. CORREA. El inicial planteamiento zubiriano de la cuestión de Dios en su artículo "En torno al problema de Dios". Influencia heideggeriana y camino propio. https://scielo.conicyt.cl/scielo. php?script=sci_arttext\&pid=S0049-34492008000200011\#t32
} 
hablando, puesto que Dios, siendo realidad absolutamente absoluta en la cual no cabe coeficiente de negatividad, debe ser trascendente, una realidad plenaria. Frente a esto, el politeísmo tiene trascendencia debilitada puesto que su realidad plenaria se vería fragmentada en varios dioses; y el panteísmo también porque la realidad divina en tanto cosmos, sería sólo un "chispazo" de lo real. En cambio en el monoteísmo se mostraría el movimiento desde una divinidad que es enigmática hacia una realidad esencialmente existente y distinta del mundo, que es fundamento de lo real y causa primera. Por ser fundamento, es realidad inteligente y volente, trascendente, absoluta. Realidad divina. El monoteísmo tendría una coherencia interna que para Zubiri se manifiesta en la superioridad intelectiva e histórica respecto de las otras opciones religiosas de la vía teísta que ya se mencionaron. Según Solari:

"La de Zubiri es una metafísica de la religión que lo lleva a defender la superioridad intelectiva e histórica del monoteísmo. Para respaldar tal superioridad, Zubiri ensaya varios argumentos a favor de un Dios único, trascendente y personal: uno cosmológico, otro antropológico y otro basado en el problema del mal. Todavía ensaya (quizás antes que todos los demás) un argumento muy peculiar que pudiera llamarse metafísico, por estar elaborado a partir de la realidad qua realidad y no de la realidad del cosmos, o del hombre, o del mal. Todas estas argumentaciones recaen en la realidad absolutamente absoluta de Dios, una realidad con unos ciertos caracteres conceptivos que podrían ser fijados racionalmente"16.

Zubiri hace entonces esbozos sistemáticos de los caracteres divinos: Dios es realidad plenaria, es vida absoluta, es un individuo absoluto, posee perfecciones de infinitud, inmutabilidad, inmensidad y eternidad, haciendo analogía al universo humano es inteligencia subsistente, tiene volición, y es persona absoluta.

"es que por ser personal, vivo, inteligente y volente, es por lo que Dios es en sí mismo, adecuadamente, una realidad fontanal última, posibilitante e impelente. Y por eso su manifestación en el poder de lo real, es lo que hace de este poder algo también último, posibilitante e impelente, constituyendo por tanto el fundamento de la religación. Tal es, a mi modo de ver, la justificación intelectual de la realidad de Dios"17

Frente a ello, toca demostrar la realidad plenaria de Dios que sería, al menos, probable. Esto se realiza a través de la experiencia monoteísta que intentará justificar la realidad de Dios, puesto que la existencia de Dios no se resuelve sólo teóricamente sino que estará involucrada la experiencia.

\footnotetext{
${ }^{16}$ E. SOLARI. La raiz de lo sagrado, pp. 388-389.

${ }^{17}$ X. ZUBIRI, 1984, en E. SOLARI, 2010, p. 398.
} 


\section{Experiencias de lo religioso}

El logos elabora y se pregunta si el poder de lo real será Dios. Esboza una idea de Dios y la razón hace que haya un acto de Dios. La fe es un momento de la razón que pide comprobar la existencia. Si bien la realidad de Dios es objetivable por medio de la marcha teórica de la razón, no es un objeto como los demás, sino un fundamento. La razón religiosa entonces no es un conocimiento como los demás sino más bien la búsqueda del fundamento plenario y trascendente del poder de lo real. La prueba de la existencia de Dios, es decir, su intelección demostrativa es puesta en marcha por la voluntad de verdad, no obstante, la respuesta no dependerá de esa voluntad sino de la intelección misma.

Esa prueba se realiza entonces a través de la experiencia, que para Zubiri será una «probación física de la realidad»:

"Experiencia no significa aquí la aisthesis, es decir no es el dato sensible. Tampoco es lo que Aristóteles llamó empeiría, el reconocimiento (mnéme) de una misma cosa en distintas percepciones; experiencia no es aquí lo empírico. Tampoco significa lo que designamos como experiencia de la vida. Experiencia es algo distinto. Es ante todo una especie de prueba a que se somete algo, una prueba que no es mera comprobación, por ejemplo, conceptiva, sino que es el ejercicio mismo operativo del acto de probar: es probación física. ¿De qué? De la realidad de algo. La experiencia es pues, probación física de la realidad.[...] El hombre, haciendo religadamente su propia persona, está haciendo la probación física de lo que es el poder de lo real"18.

Zubiri en Inteligencia y Razón (1983) distingue tres momentos en los modos de experiencia como probaciones de un "podría ser": primeramente, el establecimiento de un sistema de referencia (dada por la intelección sentiente), el segundo momento es el esbozo de posibilidades (hecho por el logos) y el tercer momento que es la probación física de la realidad (donde viene la razón). Dentro de este último momento, Zubiri categoriza cuatro formas de experiencia de lo viable. Primeramente, el experimento, que consiste en forzar a lo real campal a mostrar su índole profunda ante el experienciador. En segundo lugar, la compenetración, que sería asistir a la visión de lo real desde la propia interioridad de la persona, en donde el experienciador se instala en lo experienciado. En tercer lugar, la comprobación, que consiste ver las realidades aprehendidas en realidades postuladas por sugerencia de la realidad campal. Y en último lugar, el modo que concierne a la experienciación de mi propia realidad; la experiencia por conformación, que es una inserción de

\footnotetext{
${ }^{18}$ X. ZUBIRI. El hombre y Dios. Alianza Editorial - Fundación Xavier Zubiri: Madrid. (6 ${ }^{\mathrm{a}}$ edición), 1998, p. 95.
} 
un esbozo de posibilidades de lo que soy en mi propia realidad, es decir, tratar de conducirme íntimamente conforme a lo esbozado. Según Zubiri este es "el modo radical de experiencia de uno mismo, es la radical probación física de mi propia realidad" 19 .

"Y es que esta es una experiencia por conformación, por supuesto, pero una que implica la radical entrega y compenetración de la propia persona con la persona absolutamente absoluta. No es sólo conformación de la propia vida a la luz de Dios sino que es una experiencia de entrega de la propia persona que así se compenetra con la persona divina"20.

Así entonces "la experiencia de Dios no puede consistir ni en experimento ni en comprobación, sino en compenetración y conformación" ${ }^{21}$, puesto que ya se ha esbozado a Dios como realidad personal. Para el monoteísta entonces, Dios trascendente está presente en las cosas y la experiencia por compenetración requiere de la presencia de las dos personas. La experiencia de Dios entonces se da porque el hombre no puede dejar de encontrarse religado, fundamentado fundamentalmente en la realidad de Dios. El hombre entonces se ve siendo experiencia de Dios. En la medida que el ser humano va forjando su persona, se ve con el poder de lo real, se ve fundado en la realidad última, posibilitante e impelente, haciendo que el hombre mismo vaya constituyéndose en su realidad personal que incluye sus tres dimensiones: individual, social e histórica. Todo esto, mediado por la experiencia compenetrada de Dios y el hombre en un acto de donación y entrega, respectivamente.

"Dios es experiencia en el hombre mismo. En efecto, no es lo mismo la presencia de Dios en las cosas que en las personas. El darse de Dios a las personas tiene en palabras de Zubiri "una estructura metafísica y teologal absolutamente peculiar: no es un dar cualquiera, es una donación". [...] La donación de Dios provoca en el hombre una tensión donante que se traduce en una "entrega". En palabras de Zubiri "la forma plenaria del acceso del hombre a Dios es la entrega". La entrega es la donación personal del hombre a Dios en respuesta a la donación personal de Dios al hombre. Es la forma plenaria de la experiencia por compenetración”22.

Ahora bien, el modo más radical -según Zubiri- de probar físicamente la realidad de Dios es la experiencia por conformación. "En el proceso de búsqueda el hombre encuentra diversas posibilidades para realizarse. De ahí que entre ellas ha

\footnotetext{
${ }^{19}$ X. ZUBIRI. Inteligencia y Razón. E-book, 1983, p. 117. Obtenido de: https://kupdf.net/download/ zubiri-inteligencia-y-razon_59f122c4e2b6f51f0ac573cd_pdf\#

${ }^{20}$ E. SOLARI. La raiz de lo sagrado, p. 398.

${ }^{21}$ B. CASTILLA. "El hombre, experiencia de Dios: teología natural de Zubiri". Cuadernos de pensamiento. $\mathrm{N}^{\circ} 10,1996$, pp- 237-248, 243.

${ }^{22}$ B. CASTILLA. El hombre, experiencia de Dios, p. 246.
} 
de tomar una opción. Y esto es la libertad: la opción es la manera real y concreta de ser libre, de ser absoluto"23. Además, la fe religiosa monoteísta se vuelve parte del momento experiencial del conocimiento racional de la realidad única y personal de Dios, por eso "la religión es una experiencia por conformación porque es probación del fondo de la propia realidad en función de Dios" ${ }^{24}$.

"Dios, experiencia del hombre, al advertir que el hombre es también y sobre todo experiencia de Dios. Zubiri afirma: "no es que el hombre tenga experiencia de Dios, es que es formalmente [...] experiencia de Dios". Es decir, cuando el hombre experimenta lo más íntimo de su ser absoluto, ese absoluto es un modo de ser de Dios, que es absolutamente absoluto. El hombre por tanto, se define en cierto modo, por Dios. Este modo de experiencia sería un modo por conformación, pues es experimentarse como absoluto en un modo de experiencia de sí mismo"25.

Solari es claro en postular que la experiencia religiosa "supone un acto optativo y radicalísimo de confianza" ${ }^{26}$ porque requiere de confiar en la divinidad esbozada para determinar y orientar la propia realidad en el mundo y por ello, para Zubiri:

"Toda experiencia de Dios, debido a su estructura, es una fe. Probar el esbozo equivale a confiar en la realidad divina postulada no sólo como fundamento del poder de lo real, sino como fundamento del sentido de mi realidad (el yo) y también de la realidad del mundo (el ser)"27.

Habiendo llegado hasta este punto de la filosofía de la religión de Zubiri, ad portas de entrar en teología por lo confesional de la opción cristiana como preferencia dentro de los monoteísmos, abordaremos la música como vía de experiencia de probación física de la realidad.

\section{El modo auditivo de experienciar a Dios}

Según lo revisado, la religación al poder de lo real consiste en un hecho prereligioso dado en la aprehensión primordial. Es interesante destacar como para Zubiri, la religación se da de modo especial en el sentir auditivo, táctil y direccional. Nos detendremos en lo auditivo. La realidad se presenta de un modo auditivo, como notificante, la presentación de lo real como algo que remite a una cosa sonora. "Por el oído, la intelección es (de acuerdo con su sentido etimológico) una auscultación"28.

\footnotetext{
${ }^{23}$ X. ZUBIRI. El hombre y Dios, p. 329.

${ }^{24}$ E. SOLARI. La raiz de lo sagrado, p. 327.

${ }^{25}$ B. CASTILLA. El hombre, experiencia de Dios, p. 247.

${ }^{26}$ E. SOLARI. La raiz de lo sagrado, p. 329.

${ }^{27}$ E. SOLARI. La raíz de lo sagrado, p. 329.

${ }^{28}$ E. SOLARI. La raíz de lo sagrado, p. 118.
} 
"Todos los sentires, en especial el oído, el tacto y el sentir direccional, permiten probar racionalmente la posibilidad de la realidad absolutamente absoluta a través de su carácter trascendente y fundamental. Justo por la manifestación de la realidad divina, hay una cierta audición y un cierto tacto de Dios. Dios no se manifiesta como algo situado ante la vista, un objeto que estuviera delante, sino como esa realidad misteriosamente excesiva que se hurta a la mirada y que sólo se puede oír y tantear" 29.

Es decir, Dios pareciera presentarse con esta fuerza de imposición del poder de lo real en nuestra aprehensión de forma "audio-táctil, esto es, a un tiempo como noticia y nuda presencia por tanteo" 30 , pudiendo experimentar el fundamento de esta realidad en las cosas -y allende las cosas- como un Dios que aprehendemos sonora y táctilmente, y nos hace ir en marcha existencial e intelectiva hacia el fundamento. En esto, Solari advierte la paradoja de que en la experiencia se da "contacto con una realidad abrumadora que se escapa, noticia de esa realidad irrefragable cuya voz se intelige por una aproximación sumamente desajustada, y dinamicidad de la realidad a la que el hombre está lanzado en una dirección interminable y abismática"31.

En esto, mucho tiene que decir la fenomenología de la audición y por ende, la experiencia con la música.

Peter Szendy en su libro En lo profundo de un oído decía que nuestra escucha tiene una capacidad de abrirse paso y una fuerza de puntuación, y propone para ello hablar de otografía, de sobre-escucha, o de auscultación, puesto que todo el resto de las palabras que nombran la audición implican una pasividad que no es originaria del sentido:

“...la escucha pasiva que nos legó nuestra modernidad - esta apertura condescendiente del oído, que se presenta como la pura acogida de lo que viene- no es sino una construcción tardía erigida al precio de una neutralización, incluso de una represión de todo lo que vincula al ejercicio del oído con un marcaje..." ${ }^{, 32}$

En el caso de la audición hay una fuerza que viene de la realidad a la aprehensión (la fuerza del poder de lo real) pero también otra que va hacia la realidad luego de la modificación tónica (la fuerza de marcaje). Es decir, así como la realidad en la aprehensión vía auditiva causa una impresión en mí debido a su fuerza de imposición, así también el oído es un sentido que aprehende estimulidad y realidad

\footnotetext{
${ }^{29}$ E. SOLARI. La raiz de lo sagrado, p. 324.

${ }^{30}$ E. SOLARI. La raíz de lo sagrado, p. 324.

${ }^{31}$ E. SOLARI. La raiz de lo sagrado, p. 325.

${ }^{32}$ P. SZENDY. En lo profundo de un oído. Una estética de la escucha. Metales pesados: Santiago, 2015, p. 60 .
} 
devolviendo una fuerza de puntuación o de marcaje. Zubiri decía que por el oído la intelección era auscultación, y es que el oído al escuchar se abre una otorruta y "aquel que ausculta el cuerpo lo penetra, incluso lo perfora, lo marca y lo detalla en cuanto corpus auditivo" 33 y "lo que podrá escuchar será lo que habrá sabido hacer resonar"34. Se trata entonces de que el oído y la cognición a través de la audición es fuerza que se devuelve a la realidad para hacerle preguntas. Y la fuerza del poder de lo real al sentir auditivo le muestra exactamente aquello: que lo real es una cosa sonora, que Dios es «la voz que llama», la noticia, que no deja sino expectante al oído a preguntar y averiguar qué es lo que suena, qué dice la voz y qué noticias quiere comunicar.

La música en este sentido, es muy importante para la experiencia religiosa. La música como fenómeno intangible genera efectos y comunica significados a las personas, tanto individual como socialmente; y es paradójica: está presente y se vive a través de nuestro ser, pero a la vez no se puede tocar; llena los espacios pero no se mide; transcurre en el tiempo pero en el instante ya no está.

"La música es simultáneamente más y menos concreta, es abstracta aunque está inevitablemente hecha y experienciada de manera encarnada. La música, a diferencia del teatro, tiene un componente místico, como "abstracción corporizada" que es y a la vez que no es. Llena el espacio pero no puede ser medida, y desaparece absolutamente como si fuera una sombra una vez que se desvanece la luz. La música tiene relación con la sombra: es lo que no es de aquello que es; es manifestación de lo real que en sí mismo es real y no real. En ninguna otra práctica humana la agencia depende tan específicamente de ser y no ser; en ese aspecto la música se relaciona con la espiritualidad" ${ }^{35}$

La música y la espiritualidad se cruzan en ese aspecto y en otros. El sonido ha sido desterrado como fuente de conocimiento e interacción con la realidad debido a que nuestra lógica occidental es predominantemente eidética. La visión nos entrega una meta-posición que nos pone cerca y a la vez lejos de aquello que vemos, permitiendo un "desapego y objetividad de aquello que se presenta a sí mismo como verdad" ${ }^{36}$. Ver para creer, o mejor dicho, ver es creer. Al contrario, el escuchar es totalmente diferente:

\footnotetext{
${ }^{33}$ P. SZENDY. En lo profundo de un oido, p. 64.

${ }^{34}$ P. SZENDY. En lo profundo de un oído, p. 65.

${ }^{35}$ R. LEPPERT. "Reading the sonoric landscape" en Sterne, Jonathan (2012), The Sound Studies Reader. Routledge: New York, 2012, pp. 409-418, 412.

${ }^{36} \mathrm{~S}$. VOEGELIN. Listening to noise and silence. The Continuum International Publishing Group Ltd.: London, 2010, p. xii.
} 
"la escucha está llena de duda: duda fenomenológica del oyente acerca de lo que escucha y de él mismo escuchándolo. La escucha no nos ofrece esa meta-posición porque no hay lugar donde yo no soy simultáneamente con lo escuchado. Por muy lejos que esté la fuente, el sonido se asienta en mis oídos. No puedo escucharlo si no estoy inmerso en su objeto auditivo, que no es su fuente pero el sonido como sonido mismo"37

En la aprehensión auditiva, la realidad no se muestra como objeto delimitado visualmente, sino como "noticia" que nos lleva más allá. La escucha es dinámica. El sonido como siendo de suyo está inmerso en mí, y una filosofía del arte sonoro tiene su núcleo en este principio básico: compartimos tiempo y espacio con el objeto o evento que suena. Pensar desde la escucha entonces, implica un re-pensar las filosofías existentes de la percepción que se asientan en las nociones de objetividad y subjetividad, y en los lugares de generación de significados. La escucha implica pensar que "entre mi escucha y el objeto/fenómeno sonoro nunca sabré su verdad, sino que sólo puedo inventarla, creando conocimiento para mí" ${ }^{38}$, es decir, en la escucha yo estoy en el sonido, y no hay brecha entre lo oído y el oído, lo escuche o no lo escuche. En palabras de Salomé Voegelin:

"Los sonidos entran constantemente en mis oídos, dando vueltas por ahí, declarando su interés incluso cuando no estoy escuchando [...], el hecho de que no esté escuchándolos consciente o voluntariamente no significa que esos sonidos no den forma a la realidad como se me presenta" 39

El sonido niega la estabilidad de la experiencia sensorial. El foco de la escucha está en la naturaleza dinámica de las cosas, en los objetos perceptuales que son inestables, fluidos y efímeros. "Los sonidos son como fantasmas" que desarman las ideas visuales que son estables y nos implica como oyentes en la producción de un mundo intangible.

La escucha de música como acontece hoy en día, a través de un disco o un formato digital, genera lo que se puede llamar escucha acusmática ${ }^{41}$. La escucha acusmática es una forma de escucha descorporizada: "se dice de un ruido que se

\footnotetext{
${ }^{37}$ S. VOEGELIN. Listening to noise and silence, p. xii.

${ }^{38}$ S. VOEGELIN. Listening to noise and silence, p. 5.

${ }^{39} \mathrm{~S}$. VOEGELIN. Listening to noise and silence, p. 11.

${ }^{40}$ S. VOEGELIN. Listening to noise and silence, p. 12.

41 "Acusmático dice Larousse: Nombre dado a los discípulos de Pitágoras que durante cinco años escucharon sus lecciones escondidos tras una cortina, sin verle, y observando el silencio más riguroso. Del maestro, disimulado a sus ojos, sólo llegaba la voz a sus discípulos. [...] Hace tiempo ese dispositivo fue una cortina. Hoy la radio, y la cadena de reproducción, nos vuelven a colocar, como modernos oyentes de una voz invisible, en las condiciones de una experiencia similar" (P. SCHAEFFER. Tratado de los objetos musicales. Alianza: Madrid, 2003, p. 56).
} 
oye sin ver las causas de dónde proviene" ${ }^{42}$, de una voz que nos prohíbe en cierta forma las relaciones con lo tangible. La voz de Dios o el llamado de Dios, funciona exactamente como una escucha acusmática. A lo real se hacen las preguntas pertinentes para averiguar qué es este poder de lo real pero siempre en una audición que está impedida de ver, pues sólo puede puntear casi a modo de ecolocación $n^{43}$ este panorama enigmático donde el poder de lo real se manifiesta como último, posibilitante e impelente desde la aprehensión misma. Pensar el oído como un marcaje, una inscripción, como una "auscultación" abriéndose paso y no como un mero receptor órgano perceptivo, sino un oído completo que permite conocer unificadamente a través del logos aquello que fue recogido biauralmente entre dos repercusiones. Y esto permite entender que hayan personas que digan que Dios les habla a través de la música. Dios suena, habla, porque se le ausculta con todo nuestro ser. La música también suena; habla porque le hacemos preguntas. Y prestémosle o no atención, moldean nuestra forma de dar sentido a la realidad. El sonido y la música invitan al cuerpo a una experiencia donde el objeto/sujeto se vuelve físico, donde al escuchar estamos inmediatamente creando significado de este mundo intangible.

Ya se decía anteriormente que en la experiencia religiosa por compenetración se requerían dos personas: el hombre y Dios, y sus actos de entrega y donación respectivamente; y que en la experiencia por conformación el hombre hace su ser desde esa experiencia donde se ve siendo experiencia de Dios mismo. La escucha de la música si bien es acusmática, permite una experiencia encarnada, que tiene dimensiones prácticas y sensoriales. La escucha encarnada (embodied listening) es una escucha "que recluta al cuerpo en su totalidad, y que requiere poner atención a las formas en que las respuestas corporales se articulan con las formas narrativas contemporáneas ${ }^{\prime 44}$ como sería - en este caso- la música. Aquí, la membrana auditiva está conformada por el aparato sensoromotor con su memoria de experiencia kinestésica y visceral, siendo el oído entonces el cuerpo completo que constituye tanto el medio de expresión como el órgano auditivo en $\mathrm{sí}^{45}$. Por ello, la experiencia dada por antonomasia desde la escucha de la música es una experiencia por compenetración. La escucha encarnada compromete a todo nuestro ser personal, intelectual y físico, y a la vez que escuchamos mediante el cuerpo, expresamos en él aquello que somos, es decir, probamos físicamente la realidad escuchada. En este caso

\footnotetext{
${ }^{42}$ P. SCHAEFFER. Tratado de los objetos musicales, p. 56.

43 "Esta facultad discriminante a la que se denomina ecolocación y que, tanto en los animales como en los hombres, reside precisamente en la separación entre dos tímpanos, eventualmente amplificada. En el mundo animal, los murciélagos son los virtuosos de ese uso topográfico de la biauralidad, que les permite localizar un objeto con una infinita precisión en la otorruta de los sonidos, gracias al eco de sus gritos emitido desde su objetivo y que llega de un oído a otro con un ligero desfase interaural" (P. SZENDY. En lo profundo de un oído, p. 94).

${ }^{44} \mathrm{C}$. HIRSCHKIND. The Ethical Soundscape: Cassette sermons and Islamic counterpublics. Columbia University Press: Columbia, 2006, p. 25.

${ }^{45}$ C. HIRSCHKIND. The Ethical Soundscape, p. 27.
} 
particular, escuchamos aquello que no vemos, sensitiva, kinésica y visceralmente la música nos encarna en una experiencia completa que nos configura como personas humanas mientras nos vemos/escuchamos siendo experiencia de lo enigmático, de algo trascendente y espiritual.

Esta experiencia de escucha se entiende entonces tanto cognitiva como sensorialmente, y se logra a través de la apertura y de la volición, donde el silencio juega un papel primordial como condición de posibilidad. "El silencio como disposición, como lugar de posibilidad, no una simple ausencia de sonido"46. En la escucha religiosa se transita constantemente por el lugar místico que se le otorga al silencio y al sonido, al silencio y la música, o simplemente al silencio y a la palabra. Para el budismo, hinduismo, judaísmo, cristianismo, islam, taoísmo y otras religiones, la palabra y el silencio son primordiales en la experiencia religiosa, siendo algo característico de estos sistemas religiosos que la revelación de Dios acontece desde ambas veredas.

"La palabra y el silencio: no se trata de dos categorías que se excluyen mutuamente. Se trata de dos categorías del lenguaje que se complementan y se comprenden muy bien desde la fenomenología de la revelación" 47

La escucha partiría del silenciamiento interior como una suerte de epoché que posiciona al oyente en la escucha reducida, y de esta forma transformaría los sonidos en un objeto sonoro que serían posibles de aprehender estimúlica y realmente. En un vocabulario teológico llamaremos a esta escucha: escucha mística ${ }^{48}$. Posteriormente, vendría una segunda escucha más activa, que invita a participar, donde "se abre el corazón, literalmente el pecho, y la tranquilidad te hace querer rezar, leer la Palabra, acercarte más a Dios" ${ }^{\prime 4}$, es decir una escucha profética ${ }^{50}$. De esta forma, la escucha comenzaría su acto performático y performativo ${ }^{51}$, sumergiendo cuerpo y alma en una experiencia que conecta y provoca cambios:

\footnotetext{
${ }^{46}$ D. VILLEGAS. "La política de la escucha. Formalismo y cuerpos sonoros". Cuadernos de Música, Artes visuales y Artes escénicas, Vol. 7/1. Ene-Jun 2012, p. 159.

${ }^{47}$ A. RAMÍREZ. "La palabra y el silencio. Categorías antropológicas para desentrañar el fenómeno de la revelación y de la fe". Cuestiones teológicas, Vol. 39/92. Jul-Dic. 2012, Medellín, p. 210.

${ }^{48} \mathrm{La}$ escucha mística sería aquella que se da sin el fenómeno del sonido o de la palabra, sino en el silencio. Es la escucha contemplativa, donde se experimenta con los objetos/sujetos que se quieren conocer. En este caso, la escucha mística se basa en la experiencia de Dios, no en el diálogo, sino en otras formas de conocer, como por ejemplo a través de la escucha perceptiva.

${ }^{49}$ C. HIRSCHKIND. The Ethical Soundscape, p. 13.

${ }^{50} \mathrm{La}$ escucha profética es la que mueve a hacer algo, la escucha ética, de declamación, pronunciación, anuncio, donde se responde a un objeto/sujeto que habla, que quiere decir algo. Del gr. phemi que significa "querer decir". El profeta habla, y Dios habla. La escucha es comunicativa.

${ }^{51}$ Cfr. N. COOK. "Between Process and Product: Music and/as Performance". MTO. Vol. 7, № 2, 2001. Este autor expone la idea de entender la performance no sólo como interpretación (performática), sino como performatividad en donde la performance es generadora de cambio y significado social.
} 
"Mi disposición como escucha me pone en resonancia con la música, lo que escucho me moldea, me hace vibrar por simpatía y mi cuerpo se conforma a eso que escucha para vibrar mejor. No soy sólo un centro receptivo y mi oído, a la escucha, vibra a su vez"52

La escucha cognitiva y sensorial, se da a través del silencio y de la palabra, en un juego constante donde se transita entre conocer y sentir, entre auscultar y percibir, entre acción y contemplación, entre decir y callar, entre profética y mística, o más bien, vivenciar ${ }^{53}$ y experimentar lo religioso en una performance de la escucha que incita a la conformación de una nueva espiritualidad a través del sonido; sonido y escucha como comunicación (profética) y como percepción (mística), generándose el mismo acto performativo de una vivencia religiosa-trascendente que va más allá de objetividades e instituciones.

Finalmente podemos decir que en una experiencia humana tan abarcante e íntimamente imbricada entre tantos factores es imposible parcelar, dicotomizar, o separar un ámbito humano de otro. Las típicas divisiones entre sacro/profano, materia/ espíritu, objeto/sujeto, y muchas otras, resultan no ser suficientes para explicar el fenómeno humano en lo concerniente a la experiencia religiosa y musical. Tampoco la lectura que se pueda hacer de este fenómeno desde la primacía de una racionalidad instrumental lógico-visual. Se trata de áreas profundamente relacionadas, dialogantes, pero también tensionadas. Por eso es necesario el abordaje interdisciplinar, en este caso entre filosofía, musicología y teología. No es posible entender el rol que cumple la música examinando sólo una de ellas. El sonido y la música son fenómenos que se mueven en el terreno de lo intangible, de lo pasional y lo enigmático, al igual que la experiencia de Dios. Por ello es probable que sea medio predilecto para hacer de puente, conectando, y a la vez, permeando la experiencia mística.

Por otra parte, cabe decir que por lo aquí someramente revisado, se abren más interrogantes de las que se pueden responder, sobre todo respecto de lo que sucede con el sonido y la música en la experiencia religiosa social y comunitaria, puesto que la escucha es también "un medio para acceder a nuevas formas de conocer una

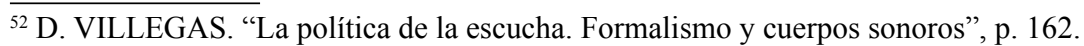

${ }^{53} \mathrm{El}$ verbo «vivenciar» no existe en inglés pero fue traducido por el filósofo Ortega y Gasset desde el alemán erleben, acuñado por Dilthey, para referirse a lo que ocurre en nuestro mundo interior. «Vivencia» apela al mundo subjetivo, y «experiencia» indiferencia el hecho fáctico (externo) con lo subjetivo (interno). Quizás lo mejor sea utilizar ambos conceptos para aplicarlos a la música, pero «vivencia» específicamente "es la que otorga especificidad a la subjetividad" y es aquella que a diferencia del evento de la experiencia, jamás se podrá generalizar. Cfr. M. BENYACAR. Lo disruptivo. Amenazas individuales y colectivas: el psiquisimo ante guerras, terrorismos y catástrofes sociales. Biblos: Buenos Aires, 2006, p. 48.
} 
cultura y de adquirir una comprensión más profunda de cómo los miembros de una sociedad se relacionan unos con otros" ${ }^{54}$. Sin embargo, este artículo pretende ser una puerta abierta a la riqueza de la comprensión de un fenómeno tan holístico como es la música, y de su vínculo profundo con esa experiencia religiosa donde Dios se escucha, es Palabra, es sonido, es voz, llamada, noticia y clamor, tanto para uno como para muchos.

En conclusión, la música conecta con la ultimidad, posibilitancia e impelencia de la divinidad-fundamento porque en su lenguaje etéreo, enigmático e intangible permite una escucha acusmática y encarnada donde todo el ser se ve comprometido con el sonido que es en nosotros, y que fantasmagóricamente nos impele a moldear y crear significado de una realidad que no conocemos, preguntando, afectándonos. Así como todos estamos religados, todos escuchamos comprometiéndonos y haciéndonos enteros desde esa escucha, querámoslo o no.

"No fue sino hasta el Renacimiento que Dios se volvió retrato. Previamente había sido concebido como sonido y vibración. [...] Antes de los días de la escritura, en la época de los profetas y epopeyas, el sentido de la audición era más importante que el de la vista. La Palabra de Dios, la historia de las tribus y otras informaciones importantes eran escuchadas, no vistas" ${ }^{\prime 25}$.

\footnotetext{
${ }^{54}$ J. GARCÍA CASTILLA. "Musicología musical. La música y el sonido como medios de investigación crítica" en El oído pensante, Vol 5/1, 2017, p. 12.

${ }^{55}$ R.M. SCHAFER. "The Soundscape" en STERNE, JONATHAN (2012), The Sound Studies Reader. Routledge: New York, 2012, pp. 95-103, 102.
} 